\title{
ABOUT IMPROVEMENT AND DEVELOPMENT OF LEGISLATIVE AND REGULATORY BASES FOR PRINTING INDUSTRY WASTE MANAGEMENT IN RUSSIA
}

\author{
Alexander Chusov \\ Vasilii Rud' \\ Alexander Komarov \\ Alexey Cheremisin \\ Vadim Davydov
}

Saint-Petersburg State Polytechnic University, Russia

\begin{abstract}
Printing industry is characterized by large variety of output production and applied technologies of its manufacturing. It leads to considerable fluctuations of technological parameters of editions, such as formats, volumes, number of printed copies and circulations. In these conditions it is necessary for the manager to respond on changes operatively, professionally and correctly. It demands from him/her knowledge of technologies, technique and specificity of printing industry.

Designs of regulatory-methodical materials for waste management in the printing industry, answering to a current state of technique and technology in this area, are necessary conditions of efficient activity of the enterprises. Unfortunately, the scientific forces which have remained in branch are estimated as very small and they experience difficulties in financing of scientific research designs. It is necessary to unite efforts of the printing enterprises for maintenance of is standard-methodical base of branch at modern level, and also to provide preparation of qualified professionals in the area under consideration.

Proposals on perfection of specifications of formation and management of printing industry waste also will be considered in the paper.
\end{abstract}

\section{KEYWORDS}

Printing industry; Waste management practice; Legislative and regulatory bases; Improvement and development. 


\section{INTRODUCTION}

The great value for maintenance of the enterprises efficient activity has an economical consumption of materials and first of all is paper. Branch specifications establish maximum permissible sizes of a waste of the papers caused by technology of printing industry, features of the applied equipment, character and number of printed copies of output production. In 1997 the State Committee of the Russian Federation on Printing approved "The Norms of Generating Waste of Paper for Industrial Technological Needs when Printing Production by Offset Way" [1], intended for definition of necessary quantity of a paper for manufacturing of printed copies number and circulations. Similarly, there were approved in 2002 "The Norms of Generating Waste of Paper for Industrial Technological Needs When Printing Multicolor Newspapers by Roll Offset Machines" [2].

Waste of printing industry is a special multi-component kind of waste consisting, except actually paper waste, from fulfilled photo-technical films, processing solutions, assembly bases, materials for manufacturing of monometallic offset printing forms, paints residues (from deep printing, offset printing, flexography, stencil printing processes and so on), offset rubber coatings, humidifying solutions, photo-polymeric printing plates, varnishes, printing foil etc. Unfortunately, now there are no properly developed norms of materials consumption on bookbinding and some other industrial operations, and also requirements to amount of waste generated.

\section{TOOLS TO INFLUENCE A SITUATION IN THE BRANCH}

Improvement and development of waste management methods in printing industry along with waste management tools (including regulatory base improvement) are to promote achieving good manufacturing practice in the branch. Most importantly should be improvements in regulations concerning measurement of wastes across the industry. To produce a positive effect it is significantly to solve problems arising in the way in which printers deal with waste issues.

To raise professional competence level of printing industry personnel, educational providers can use many of the lessons and case studies identified well into the future, including learning legislative base in the branch as well. As a consequence the usefulness of the information to be gained in this area could help to aid the printing industry.

The general directions for legislative and regulatory bases should provide the next important positions [1], [2]:

1. Regulations establish values of generated waste of the paper, paints, solvents and other used materials caused by technology of polygraph industry regulated by technological instructions operating in branch for various processes, by features of the applied equipment, by character and numbers of exemplars of output production and other factors.

2. Specifications are used for definition of necessary amount of materials for printing when manufacturing circulations, for calculations of materials amount being given out to 
workshops; on their basis reports for publishers are to be made about quantity of the spent materials for circulation issue.

3. At each enterprise the rational utilization of materials and their economy at all stages of the technological process should be provided with taking into account specifics of technological process in every separate case.

4. Branch regulations of waste generation are maximum permissible indicators of values of waste for industrial technological needs. Their observance is recommended for all enterprises and for the branch organizations, and also for polygraph sites and workshops, available in other branches, irrespective of their departmental subordination.

Regulations are intended for application of materials for printing corresponding to: standards and specifications, way of printing, kind of production, applied equipment, format of editions with taking into account design features of the printing equipment.

The materials should be prepared for printing according to requirements of technological instructions.

5. At use in one edition of papers with the various technological properties, application of not profile paper (for example, typographical one for offset printing), and also at delivery to the enterprises sub-standard paper (wrapping, selection from typographical, etc.) bilateral statements of the enterprises and publishing houses are drawn up.

6. Specifications should not include a waste and the losses of materials caused by malfunctions in the manufacture and supply organization (unsatisfactory transportation, wrong storage of materials in warehouses).

In case of supply of paper with damages causing a waste from preparation of rolls for printing over the established specifications, these waste above permitted standard are formalized by acts when due hereunder with the aim of their indemnification by high-grade paper.

7. When detecting by the enterprises discrepancy of quality received materials to requirements of standards, acts are drawn up in relation to poor-quality materials.

8. When calculating paper amount for circulation under a standard sheet it is necessary to understand the sheet corresponding to the size of the printing form; under paint-and-print it is necessary to understand a standard sheet sealed by one paint from one side of the sheet. As standard sheet parties it is necessary to understand the form as the printing form fixed at one forms cylinder.

Amount of paper waste for preparation of forms for printing (fitting) it is defined in standard sheets, under other articles waste it is defined in percentage of the paper amount necessary for printing circulation (without a waste). Waste amount when cutting a rolled paper on sheets is estimated from total of a cut paper. 
9. In case if the edition is printed from the several duplicated (identical) forms or some times repeats on one printing form, when defining paper waste amount the circulation of editions is divided on a number of such duplicated forms.

10. When printing on a paper of the second grade, to norms of a waste it is added $0,1 \%$ from the general expense of a paper on printing process (irrespective of number paint-and-print).

11. The net weight of a paper roll of import manufacture includes weight of bush sleeve.

12. On editions, which registrations on character and technological process are carried out under a special agreement or special quotations, specifications of a waste are established by a separate agreement.

13. At presence at enterprises of separate kinds of equipment, on which branch norms of a waste are absent, the local temporal norms are developed with period of validity till one year.

14. In offset printing specifications are established with taking into account circulation wear resistance of printing forms:

- for the monometallic forms made with use special plates:

without heat treatment:

when printing by sheet and rolled machines it is 50 thousand prints;

with heat treatment:

when printing by sheet and rolled machines it is 100 thousand prints;

- for preliminary sensitive-made monometallic plates with complex electrochemical processing domestic and import manufactures by sheet and rolled machines

without heat treatment it is 100 thousand prints;

with heat treatment it is 400 thousand prints;

- for bimetallic forms with chrome etching it is 1 million prints.

In case of use of the printing equipment with the large term of operation, circulation wear resistance printing forms decreases twice.

The flow of materials and work through a printer is remarkably similar, the main difference being the type of printing operation being undertaken. So the main printing processes can be substituted in the printing operations box with the other issues remaining virtually unchanged. A typical printer has the following process flow chart (see Figure 1): 
Increasing landfill prices, regulatory pressures and customer awareness are signals that things could get worse from a cost of production perspective. A smart printer may find that by jumping ahead and using advance waste minimisation methods can give a commercial advantage.

Waste minimisation assists in reducing commercial pressures by:

1. Cutting costs largely due to the savings from diverting wastes from landfill disposal to recycling.

2. Lifting the environmental image of the company and therefore attracting new environmentally sensitive customers.

3. Improving staff moral, therefore productivity we do more than just make money for the company and it shareholders, we also look after the environment.

4. Reducing regulatory pressures on the individual company and on the industry as a whole.

5. Improving public perception of the printing industry as one of green and clean.

Most of the market leaders in waste and environmental management in the printing industry are at the larger end of the market. Larger companies have more resources to invest in identifying and implementing efficiency gains. The printing industry is no different from many other industry sectors, with a sharp difference between waste management practices of large and small printers. Figures 2 and Figure 3 show the differences between an efficient and wasteful printer. An efficient printer actions waste management and minimisation principals at every step of the printing process. Many printers are between these two extremes. For example, many printers recycle large quantities of recoverable paper from the printing operation, but ignore the wastes from the other processes. To improve the situation in the printing industry it is necessary to develop multi-criteria approach allowing estimation and control waste generation in all the stages of manufacturing process with planning their efficient utilization and recycling in the end. And one of the most important mean to achieve this effect is improvement of legislative and regulatory bases [3], [4], [5], [6], [7], [8]. 
Linnaeus ECO-TECH '10

Kalmar, Sweden, November 22-24, 2010

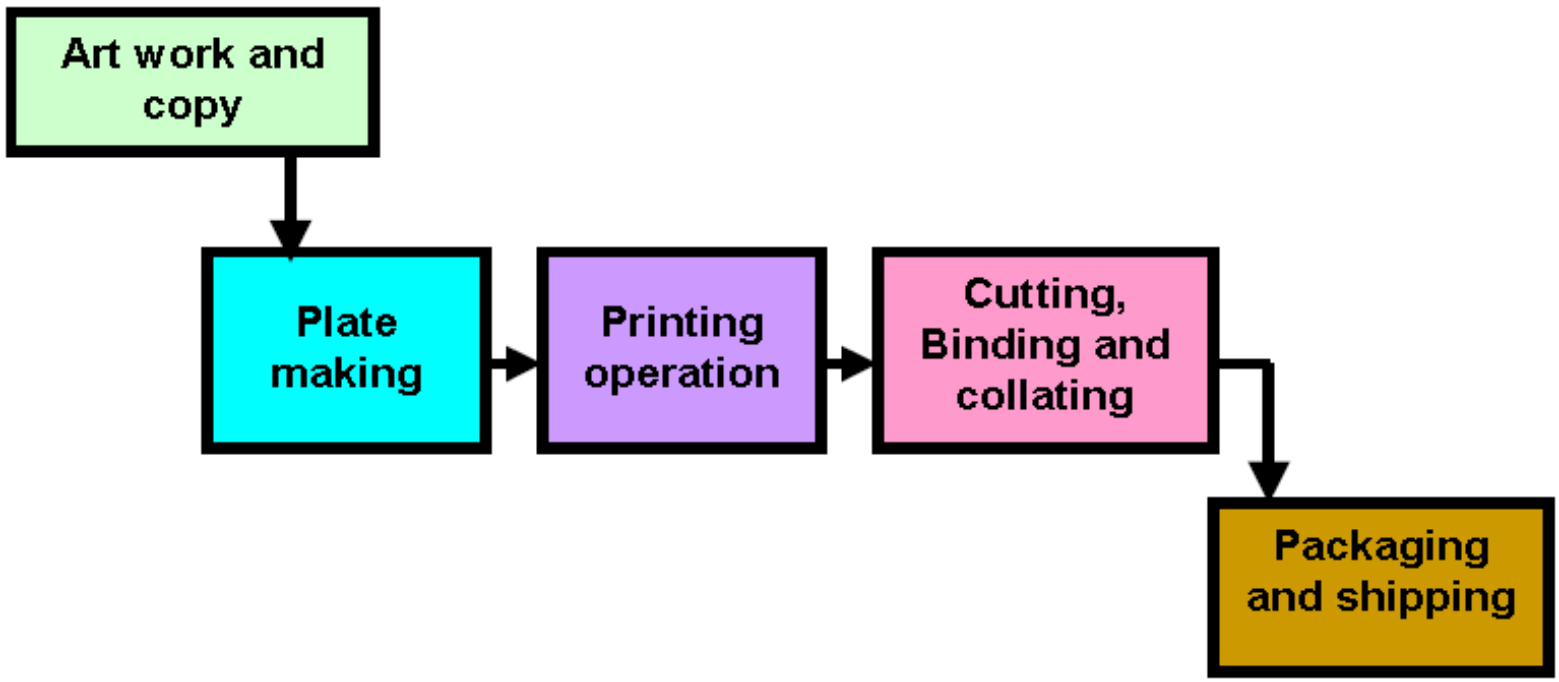

Figure 1. Process Flowchart of a Typical Printer. 
Linnaeus ECO-TECH '10

Kalmar, Sweden, November 22-24, 2010



LANDFILL AND SEWER DISP OSAL

Figure 2. A Wasteful Printer's Profile. 
Linnaeus ECO-TECH ' 10

Kalmar, Sweden, November 22-24, 2010

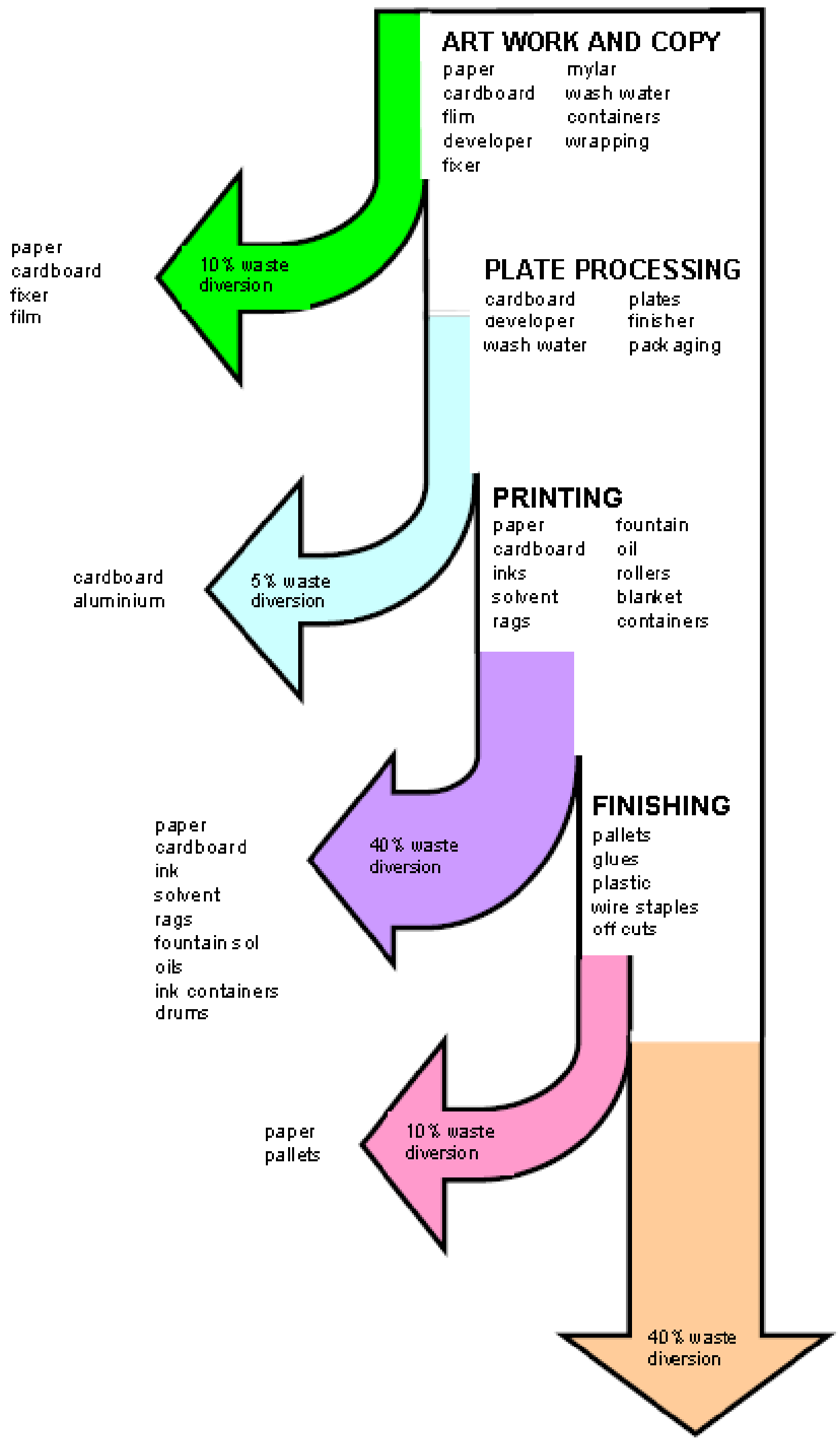

LANDFILL AND SEWER DISPOSAL

Figure 3. An Efficient Printer's Waste Profile. 


\section{CONCLUSIONS}

A main outcome of this paper is the recognition that one of the significant obstacles for printing companies to improve their environmentally friendly practices is a lack of perfect legislative and regulatory bases. Change in attitude towards becoming more efficient and productive through waste reduction strategies can lead to savings and improvements in printing industry. A set of state and regional laws for printing companies to adopt waste minimisation techniques should promote to change incorrect waste management practice in the branch. Promotion of these legislations and regulations is going to help lifting the public environmental image and profitability of printing industry in Russia.

\section{REFERENCES}

[1] The Norms of Generating Waste of Paper for Industrial Technological Needs When printing production by offset way. Approved by an Order No 154 of Russian State Committee on Printing from December 29, 1997. The norms have been valid from July 1, 1998.

[2] The Norms of Generating Waste of Paper for Industrial Technological Needs When Printing Multicolor Newspapers by Roll Offset Machines. Approved by an Order No 155 Ministry on the Matters of Printing, Broadcasting and Mass Media of Russia from August 20, 2002.

[3] Australian Recovered Paper Specifications (AuRPS). Handbook. Published by the Australian Council of Recyclers through funding from the National Packaging Covenant Transitional Arrangements Program www.acor.org.au. December 2002. 15 pp.

[4] Australian Environment Business network. Waste Reduction in the Printing Industry. Final Report. May 2003. 45 pp.

[5] The European e-Business Market Watch. Sector Report No. 03-I (July 2005) ICT and Electronic Business in the Publishing \& Printing Industry. Key issues and case studies. European Commission Enterprise \& Industry Directorate General. 89 pp.

[6] Hazardous Waste Management for Printers, New York DEC, Division of Hazardous Substances Regulation, Bureau of Pollution Prevention, September 1991 Draft.

[7] Fact Sheet: Management of Solvents and Wipes in the Printing Industry, University of Wisconsin-Extension, Solid and Hazardous Waste Education Center. 425.WP.9410, 1994.

[8] Fact Sheet: Waste Reduction Opportunities for Printers, University of WisconsinExtension, Solid and Hazardous Waste Education Center. 425.WP.9408, 1994. 